\title{
Interhemispheric neural summation in the split brain: effects of stimulus colour and task
}

\author{
Matthew Roser ${ }^{\mathrm{a}, *}$, Michael C. Corballis ${ }^{\mathrm{b}}$ \\ a Department of Psychological and Brain Sciences, Center for Cognitive Neuroscience, Dartmouth College, Dartmouth, NH 03755, USA \\ b Department of Psychology, Research Centre for Cognitive Neuroscience, University of Auckland, Auckland, New Zealand
}

Received 23 January 2002; received in revised form 18 October 2002; accepted 18 October 2002

\begin{abstract}
Four split-brained subjects, two subjects with agenesis of the corpus callosum, and 14 normal subjects performed two tasks requiring responses to red or green disks, briefly presented either singly in the left visual field, singly in the right visual field, or simultaneously in both visual fields. In Experiment 1, simple reaction times to these stimuli, regardless of colour, were recorded (the Go-Both Task), and found to be faster to bilateral-redundant stimulus pairs, than to single stimuli. This so-called "redundancy gain" was much larger for acallosal or split-brained subjects than for normal subjects and exceeded the predictions of a race model, implying neural summation. Experiment 2 used the same stimuli, but subjects were required to respond only to stimuli of a designated colour (the Go/No-Go Task). Redundant target stimuli produced neural summation, while stimuli pairs that included a non-target stimulus did not. These results suggest that neural summation in the acallosal or split brain involves the convergence of response-associated activation, and that redundant sensory processes are not sufficient.
\end{abstract}

(C) 2002 Elsevier Science Ltd. All rights reserved.

Keywords: Redundancy gain; Commissurotomy; Callosotomy; Callosal agenesis

\section{Introduction}

The observation that reaction times (RTs) to visual stimuli are faster when more than one stimulus is presented is well supported [23,26,28]. This effect, known as the redundancy gain, has two possible explanations, probability summation and neural summation. Probability summation describes the average RT benefit that occurs when the faster of two independent processes ultimately controls the response, compared to when a single process is in operation. This has been likened to a race between the two processes, and has therefore, been termed the race model $[23,31]$. Neural summation involves the combination of activation from redundant processes, so that a criterion level of activation, necessary for the initiation of a response, is reached sooner than if a single process was in operation [23]. Neural summation is implied if the observed redundancy gain exceeds the prediction of the race model.

While the redundancy gain is a reliable effect, evidence for neural summation is less so. Although race-model violations have been observed in many experiments, those pro-

\footnotetext{
* Corresponding author. Tel.: +1-603-646-9242; fax: +1-603-646-1181.

E-mail address: matthew.roser@dartmouth.edu (M. Roser).
}

duced by neurologically normal subjects are usually small, at least when the task is one of simple detection or simple RT. In fact, the redundancy gain shown by normal subjects often falls well below the prediction of the race model $[6,7,32]$. By contrast, much larger race-model violations have been observed in RT data from split-brained or acallosal subjects $[7,17,30,32]$. Paradoxically, these large redundancy gains have occurred when redundant stimuli were presented with one copy in each visual hemifield, resulting in each hemisphere only receiving a single stimulus. Furthermore, bilateral presentation of redundant stimuli seems to be a necessary condition for neural summation in at least one callosotomized subject [32], and two commissurotomized subjects [17], as presentation of unilateral redundant stimuli did not result in race-model violations.

The large redundancy gains shown by acallosal or splitbrain subjects occur despite the fact that these subjects show abnormally prolonged RTs to single stimuli presented in the visual hemifield that is contralateral to the response hand, relative to RTs to single stimuli presented in the visual hemifield that is ipsilateral to the response hand. This crossed-uncrossed difference (CUD) is around $4 \mathrm{~ms}$ in callosally intact subjects, several times longer in acallosal subjects $(\sim 30 \mathrm{~ms})$, and longer still in surgically split-brained 
subjects ( $\sim 70 \mathrm{~ms})$. While the relatively short CUD of normal subjects is thought to reflect callosal transmission time, probably of motor or decisional information since it is unaffected by manipulation of luminance or eccentricity $[6,11]$, the longer CUDs of acallosal or split-brained subjects may be due to slower sub-cortical transmission [4], or the use of the ipsilateral motor pathway in making responses [32]. Furthermore, previous studies have suggested that the size of the redundancy gain generally increases with the degree of cortical disconnection, as indexed by the crossed-uncrossed difference $[17,33]$. This relationship contrasts with the lack of correlation between the CUD and the redundancy gain shown by callosally intact subjects, suggesting that split-brained or acallosal subjects do not lie at one extreme end of a continuum in which longer CUD is accompanied by greater redundancy gain [6].

As the brains of split-brained or acallosal people are divided at the cortical level by surgery or pathology, neural summation in these subjects must occur via sub-cortical pathways, either at a sub-cortical location itself, or at the level of the cerebrum following sub-cortical interhemispheric transmission. The questions of where in the split-brain summation occurs, and the nature of the activation summated, are at present unresolved. Summation may involve products of cortical processing, such as response-preparation signals. For example, Reuter-Lorenz et al. [32] have suggested that bilaterally redundant stimuli may result in response-preparation processes occurring in both hemispheres, which then remove tonic response inhibition and result in a redundancy gain. Alternatively, sensory activation may be summated at a relatively early stage of the pathway to response.

Summation involving sensory activation is suggested by studies showing effects of stimulus properties on the redundancy gain. Corballis [7] has shown that the large redundancy gains produced by three surgically split-brained people were reduced to a level which did not exceed the race model when stimuli were presented as hue changes equiluminant with the background. As equiluminant stimuli are probably invisible to the superior colliculus, this result suggested that the involvement of this visually responsive midbrain structure may be necessary for large redundancy gains that violate the race model to occur. This hypothesis could not, however, be extended to an acallosal subject who was also tested, and who showed a slightly larger redundancy gain under equiluminant conditions. Further testing of a group of 58 normal subjects showed equivalent redundancy gains for equiluminant and luminance-contrast conditions, although a component analysis suggested that the redundancy gain in the callosally intact brain may involve different brain systems under these two conditions [6]. Furthermore, neural summation in the split brain has been found to be unaffected by mid-line symmetry of bilateral-stimuli pairs, suggesting that, while collicular activation may be necessary, topographic mapping, such as that which occurs at the superior colliculi, is not important [33].

The present study includes two experiments designed to further elucidate the nature of the activation that produces the large redundancy gain in the acallosal or split brain. In Experiment 1, unilateral and bilateral-redundant luminant

\section{$\underline{\text { Go-Both Task }}$}
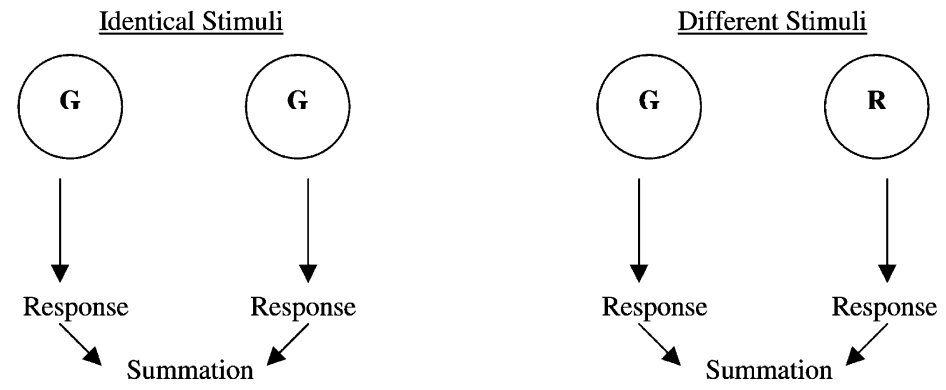

Go/No-Go Task (Green Target)
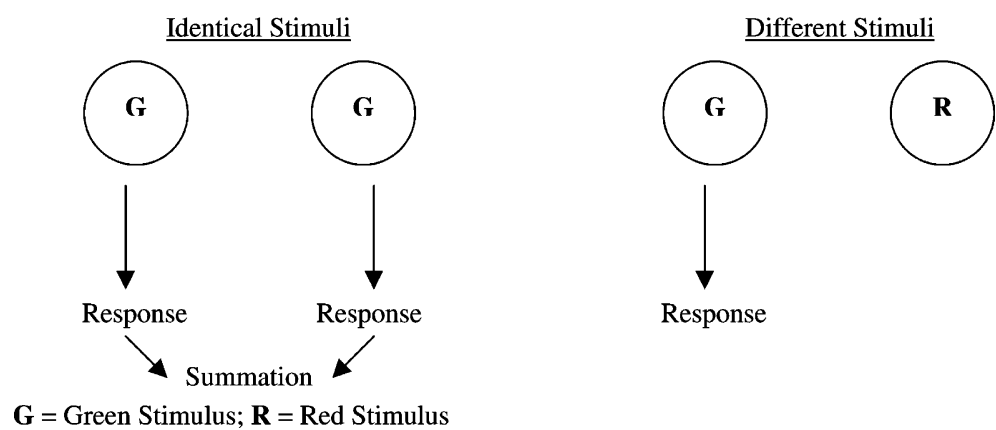

Fig. 1. The summation of redundant response processes in the Go-Both and Go/No-Go Tasks with same- or different-colour stimuli. 
stimuli were presented. Redundant stimuli could be either of identical colour, or of different colour. Subjects were required to respond regardless of stimulus colour, a task we refer to as the "Go-Both Task". While earlier studies suggest that different stimuli can produce a redundancy gain in normal subjects $[14,16,22,23]$, this experiment should determine whether the large race-model violations observed in surgically split and acallosal subjects are also apparent with redundant stimuli that differ in colour. Since the superior colliculi are thought to be insensitive to wavelength [29], an effect of colour similarity on the redundancy gain would imply cortical involvement. Conversely, if summation involves sensory activation at the sub-cortical level, redundancy gains should be equivalent for redundant-stimuli displays of same- or different-colour pairs.

The Go-Both Task also acts as a control task for Experiment 2, in which subjects were instructed to respond only to stimuli of a designated target colour. We refer to this as the "Go/No-Go Task". As the stimuli have identical visual properties in both experiments, but differing response attributes, between-task comparison of the effect of stimulus redundancy on RT should reveal whether redundant response processes are necessary for redundancy gains to occur, or whether sensory redundancy alone is sufficient. If sensory activation is summated at the level of the superior colliculus, different-colour stimuli pairs should produce redundancy gains in each of the two tasks. Conversely, if redundant response processes converge, summation should occur for same- and different-colour pairs in the Go-Both Task, but only when redundant target stimuli are displayed in the Go/No-Go Task. This logic is represented in Fig. 1.

\section{Experiment 1}

In this experiment, the Go-Both Task was used to assess whether redundant stimuli had to be of identical colour for neural summation to occur. An effect of colour similarity on the redundancy gain would imply cortical involvement, as sub-cortical regions involved in vision are not thought to discriminate wavelength. This experiment also acts as a control task for the second experiment, in which target stimuli were identified by colour.

\subsection{Method}

\subsubsection{Subjects}

We studied a total of 20 subjects, four of whom had undergone surgical section of the corpus callosum. Two others had agenesis of the corpus callosum and 14 were assumed to be neurologically normal. The split-brained subjects are known by their initials as J.W., V.P., N.G. and A.A., while the acallosal subjects are known as M.M. and J.P.

2.1.1.1. Split-brained subjects. J.W. is a 45-year-old right-handed male who underwent a staged callosotomy at the age of 26 for the control of intractable epilepsy. V.P. is a 47-year-old right-handed woman who also had staged callosal surgery. The details of these two subjects' neurological profiles can be found in Gazzaniga et al. [12]. Sagittal MRI demonstrated complete resection of the corpus callosum in J.W, with sparing of the anterior commissure. In case V.P., sagittal MRI revealed residual callosal fibres in the area of the splenium and rostrum and an intact anterior commissure. Subsequent MRI examination has not revealed any splenial residual fibres (Paul M. Corballis, personal communication). N.G. is a 66-year-old right-handed woman and A.A. is a 49-year-old right-handed man. Both these subjects underwent a complete cerebral commissurotomy where the corpus callosum, massa intermedia and both the anterior and hippocampal commissures were severed. The completeness of the callosotomy in these two patients was later confirmed by magnetic resonance imaging [1]. The anterior commissure was not observed in this study, but for technical reasons it was not possible to tell whether it was completely severed.

2.1.1.2. Acallosal subjects. M.M. is a 40-year-old right-handed woman. She was slow to reach all developmental milestones, and following the birth of her first child at age 17 she suffered epileptic seizures. MRI scans taken at the age of 34 revealed complete absence of the corpus callosum and an anterior commissure that fell within normal size limits. No other abnormalities were reported [9]. J.P. is a 33-year-old right-handed woman. MRI scans showed the corpus callosum to be entirely absent and prominent antero-posteriorly oriented bands of white matter (bundles of Probst) were observed. J.P.'s anterior commissure is approximately nine times normal area in cross-section and the massa intermedia is slightly more prominent than usual.

2.1.1.3. Normal subjects. The 14 control subjects included the experimenter and 13 paid student volunteers. There were 4 females and 10 males with ages ranging from 20 to approximately 40 years. All but one of these subjects were under 30 in age. Three were left-handed (all male) and the remainder were right-handed. All had normal or corrected-to-normal visual acuity.

\subsubsection{Experimental set-up}

Stimuli were presented on an SVGA monitor using the software package Micro Experimental Laboratory [35]. Due to the need to test subjects at different locations, different monitors were used for different subjects. One monitor was used for N.G. and A.A. Separate monitors were used to test J.W., V.P. and M.M. and another was used to test J.P. and the 14 control subjects. J.W. was seated with his eyes at $57 \mathrm{~cm}$ from a $15 \mathrm{in}$. screen. All other subjects were seated at $63 \mathrm{~cm}$ from a $17 \mathrm{in}$. screen. Care was taken to ensure that visual angles were strictly preserved between experimental set-ups and that screen luminance and ambient room illumination was roughly equivalent for all testing situations. 


\subsubsection{Stimuli and procedure}

Stimuli were filled circles of either pure red or pure green that subtended a visual angle of $1.03^{\circ}$. Stimuli were presented on a black background and were flashed to mirror-symmetric positions to the left and right of a central fixation cross. The inner edge of each stimulus was $5.5^{\circ}$ of visual angle from the fixation cross. The eccentricity of these stimulus locations was sufficient to ensure that stimuli were displayed outside any visual field overlap [10]. Stimuli were thus, presented only to the hemisphere contralateral to the visual field in which they appeared.

A flicker-fusion task was completed prior to beginning the experiment, in order to roughly match the two stimulus colours for luminance. Subjective equiluminance was defined as the luminance value for a green stimulus that was least often judged to have produced a flicker when rapidly alternated with a red stimulus of invariable luminance. Equiluminance values were assessed for all subjects, except for A.A., for whom equiluminance was set at the value determined by J.P. and three of the control subjects. When asked, A.A. reported not noticing any difference in brightness between the two stimulus colours.

The experiment consisted of 720 trials in total, 360 with each hand in alternating blocks of 45 trials. This yielded 40 trials for each of nine different displays with each hand. There were eight different stimuli-present display types, and catch trials, in which no stimuli were presented. Stimuli were either unilateral (for example, a single green stimulus in the left visual field), or bilateral (two stimuli of same or different colour, one in each of the left and right visual fields). There were, therefore, four different unilateral stimulus displays (Green Left, Green Right, Red Left, Red Right) and four different bilateral displays (Green + Red, Red + Green, Green + Green, Red + Red). A practice block of 10 trials was completed prior to commencing the experiment.

Blocks were initiated by subjects pressing the spacebar. The fixation cross was presented and remained on the screen for a randomly selected delay time before the stimuli were presented. Delay times were $300,400,500,600$ or $700 \mathrm{~ms}$ in duration and each of the eight stimuli-present display types was paired five times with each of the delays. This variable interval was used to decrease the predictability of stimulus arrival, forcing subjects to wait for the stimulus, rather than attempt to anticipate its appearance. Stimuli were flashed for $133 \mathrm{~ms}$ at the end of the delay period. Following the offset of the stimuli, the subjects had $1000 \mathrm{~ms}$ in which to make a response. RTs were recorded from the onset of the stimuli and responses made while the stimuli were still on the screen were treated as anticipations and discarded. On catch trials the fixation cross was presented alone for $700 \mathrm{~ms}$. On all trials there followed a period of $1000 \mathrm{~ms}$, during which the screen was blank. Responses to stimuli, regardless of colour, could be made during this period by pressing the spacebar. If a response was made to the presentation of a stimulus, a $500-\mathrm{Hz}$ tone sounded for $200 \mathrm{~ms}$. If a response was made on a catch trial, or no response was made to a presented
Table 1

Mean number of errors made by control subjects and total errors made by each split-brained or acallosal subject for the Go-Both Task

\begin{tabular}{lcc}
\hline Subject & Misses & Catch \\
\hline Controls & 0.86 & 0.86 \\
N.G. & 141 & 2 \\
A.A. & 83 & 7 \\
J.W. & 4 & 2 \\
V.P. & 2 & 1 \\
M.M. & 1 & 1 \\
J.P. & 0 & 1 \\
\hline
\end{tabular}

stimulus before $1000 \mathrm{~ms}$ elapsed, a $200-\mathrm{Hz}$ tone sounded for $500 \mathrm{~ms}$, indicating an error. At the end of each trial there was a $500 \mathrm{~ms}$ delay before the fixation cross reappeared. Trials in which an error was made were rerun to ensure equal numbers of RTs were collected for each display type.

\subsection{Results}

\subsubsection{Errors}

Errors consisted of failing to respond to a presented stimulus (a miss) and responding on a catch trial. The mean number of errors made by control subjects and the total number of errors made by each split-brained or acallosal subject are shown in Table 1.

The control subjects made very few errors, on average. The split-brained or acallosal subjects had higher error rates, although the relatively low catch trial error rates suggest that these subjects were not responding indiscriminately on each trial, but rather were genuinely trying to respond to the presentation of the target. This performance was far from perfect, however, for the two commissurotomized subjects N.G. and A.A. These two subjects had trouble responding to targets presented in the visual field contralateral to the hand used for response. All but four of the stimuli missed by N.G., and all but six of the stimuli missed by A.A., were crossed unilateral targets. A.A.'s miss rate was inflated by the multiple repetition of the last two trials of a block in which the right hand was used for response. On these two trials, stimuli were presented in the left visual field and A.A. repeatedly claimed to not see the targets. These two trials were eventually removed from the dataset after A.A.'s repeated failure to make a response.

\subsubsection{Reaction times}

Median RTs were calculated from the onset of the stimulus, for each combination of response hand and display condition. This was done separately for each control subject and each of the split-brained or acallosal subjects. Overall means of the median RTs were then calculated for the control group as a whole, and for each of the split-brained or acallosal subjects. A.A.'s median RTs with his right hand were calculated from a reduced dataset, due to his failure to fully complete one block. The overall crossed-uncrossed difference was calculated by subtracting each subject's median 
Table 2

Average median RT, CUD and redundancy gain in milliseconds for all subjects in the Go-Both Task

\begin{tabular}{llrl}
\hline & Average median RT & CUD & Redundancy gain \\
\hline Controls & 271 & 3 & $15^{* *}$ \\
N.G. & 397 & $137^{* *}$ & $35^{*}$ \\
A.A. & 534 & $97^{* *}$ & $44^{* *}$ \\
J.W. & 370 & $80^{* *}$ & 14 \\
V.P. & 367 & $48^{* *}$ & $36^{*}$ \\
M.M. & 339 & $25^{* *}$ & 24 \\
J.P. & 289 & $28^{* *}$ & 15 \\
\hline
\end{tabular}

* $P<0.05$.

** $P<0.01$.

RT to uncrossed stimuli, or those appearing in the visual field ipsilateral to response hand, from the median RT to crossed stimuli. Redundancy gain was calculated by subtracting each subject's median RT to bilateral trials from the shorter of the two median RTs to the corresponding unilateral trials. Table 2 shows the CUDs, redundancy gains and median RTs for all subjects averaged across display condition and response hand.

2.2.2.1. Crossed-uncrossed difference (CUD). A one-sample $t$-test was carried out on the calculated CUDs from the control subjects' data. The mean CUD differed significantly from zero only on a directional test, $t(13)=1.794, P=$ 0.096 .

Separate independent-samples $t$-tests compared each split-brained or acallosal subject with the controls, so that each split-brained or acallosal subject was treated as a separate group. Each analysis therefore, treated the individual split-brained or acallosal subject's CUD as a sample mean from a hypothetical population, and tested whether this sample mean differed from the mean of the normal sample. Interactions with the factor of group would therefore, indicate differences between each subject and the controls. Analyses of this type have been used previously to compare a split-brained subject to a group of normal controls [5]. All of the split-brained or acallosal subjects produced significantly greater CUDs than the control group. Significance (at $\alpha=0.01$ ) for each of these group comparisons is indicated by double asterisks alongside the subjects' overall CUDs shown in Table 2.

2.2.2.2. Redundancy gain. Redundancy gains were calculated separately for each combination of hand and bilateral stimulus display. This was accomplished by subtracting the median RT to the bilateral display from the faster of the RTs to the two corresponding unilateral displays. Overall mean redundancy gains for same- and different-colour stimuli displays were then calculated for each subject. A repeated-measures analysis of variance, including the factor of colour similarity, was carried out on the redundancy gains produced by the 14 control subjects. Control subjects produced an overall redundancy gain of $15 \mathrm{~ms}$ that was sig- nificantly greater than zero (significance indicated by double asterisk in Table 2). There was no effect of stimulus colour; the redundancy gain averaged $15 \mathrm{~ms}$ for both sameand different-colour stimuli pairs.

Separate analyses compared each split-brained or acallosal subject with the control group. Asterisks, on Table 2, indicate significant group comparisons for these subjects.

Two commissurotomized subjects, N.G. and A.A., showed significantly greater redundancy gains than the control subjects, as did callosotomized subject V.P.

Acallosal subject M.M. produced a larger overall redundancy gain (24 ms) than the control group, but this difference was not significant. However, the factor of group interacted with the stimulus contrast, $F(1,13)=10.909, P=$ 0.006. Unlike the control group, M.M. showed bigger redundancy gains for same-coloured displays $(32 \mathrm{~ms})$ than for different-coloured displays (16 ms).

\subsubsection{Cumulative probabilities}

Cumulative probabilities were calculated for each combination of unilateral-stimuli and the corresponding bilateral-stimuli display. This was done separately for each hand. The race model was defined as follows. If responses to bilateral $\left(S_{\mathrm{ic}}\right)$ stimuli are the result of a race between two independent processes initiated by the stimuli ipsilateral $\left(S_{\mathrm{i}}\right)$ and contralateral $\left(S_{\mathrm{c}}\right)$ to the responding hand, the probability $P_{\text {ic }}$ of a response being made by time $t$ is given by

$P_{\mathrm{ic}}=P_{\mathrm{i}}+P_{\mathrm{c}}-P_{\mathrm{i}} P_{\mathrm{c}}$

where $P_{\mathrm{i}}$ is the probability of a response being made in time $t$ to a unilateral stimulus located ipsilaterally to the responding hand and $P_{\mathrm{c}}$ the probability of a response being made in time $t$ to a unilateral stimulus located contralaterally to the responding hand [23]. Thus, if responses to bilateral-stimuli are speeded relative to unilateral-stimuli to such an extent that $P_{\text {ic }}>P_{\mathrm{i}}+P_{\mathrm{c}}-P_{\mathrm{i}} P_{\mathrm{c}}$, then the race model has been violated. This can be tested by plotting the expression $P_{\text {ic }}-$ $\left(P_{\mathrm{i}}+P_{\mathrm{c}}-P_{\mathrm{i}} P_{\mathrm{c}}\right)$. If at any time the value exceeds zero, it can be concluded that probability summation is insufficient to account for the observed redundancy gain.

It should be noted that this equation for the race model assumes that the processes initiated by the unilateral-stimuli are independent. This assumption can be relaxed by rearranging the race model to the following inequality:

$P_{\text {ic }} \leq P_{\mathrm{i}}+P_{\mathrm{c}}$.

We have preferred the full race-model equation because it allows for the cumulation of probabilities over the entire RT range, not just over the range $P_{\mathrm{i}}+P_{\mathrm{c}} \leq 1$, but our conclusions would be essentially the same in either case.

The eight plots included in Fig. 2 show the mean violation of the race model by the 14 control subjects. Any point above the horizontal line represents a violation of the race model for that bin. The control subjects produced only small 

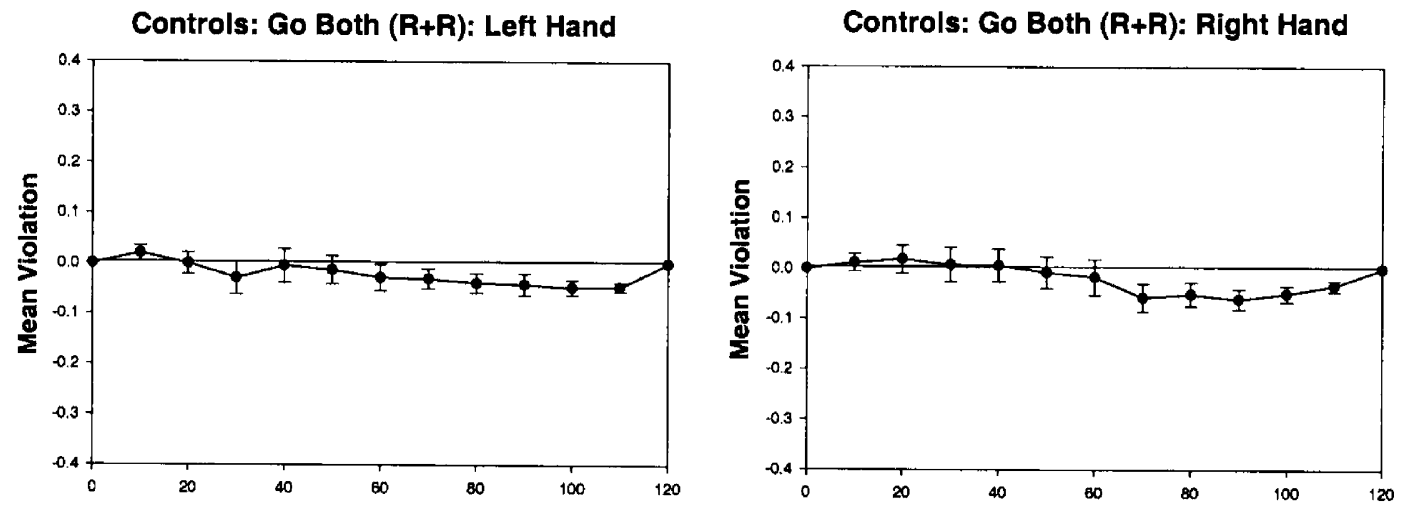

Controls: Go Both $(G+G)$ : Left Hand

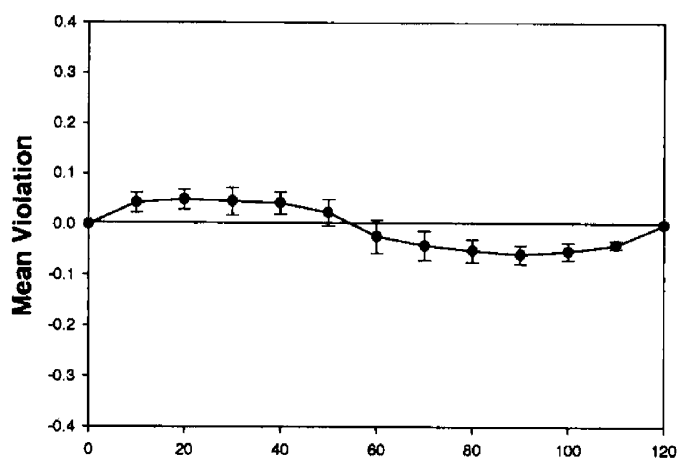

Controls: Go Both $(G+G)$ : Right Hand

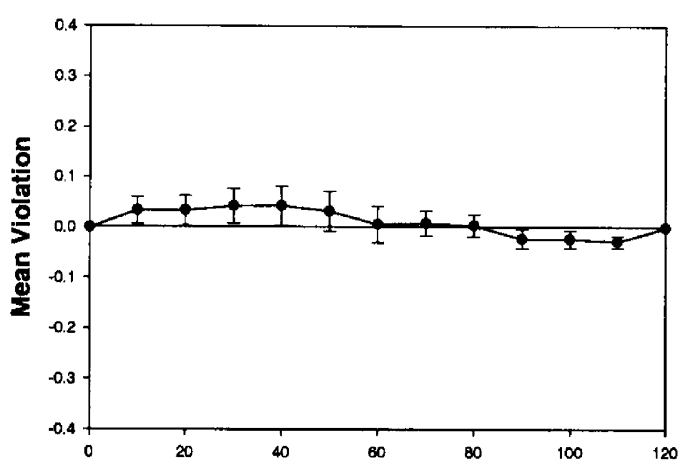

Controls: Go Both $(R+G)$ : Left Hand

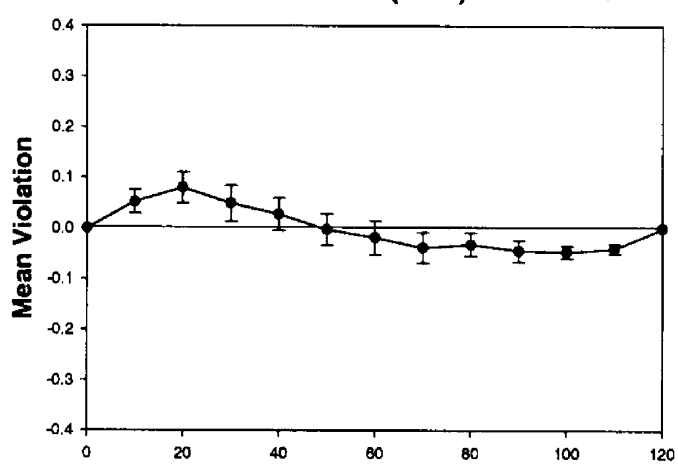

Controls: Go Both $(R+G)$ : Right Hand

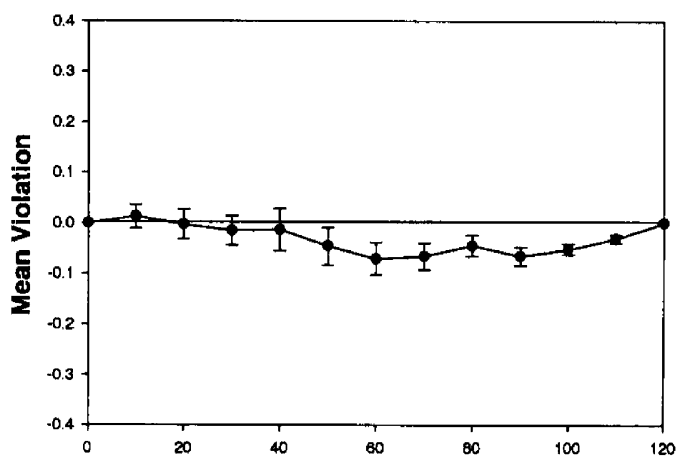

Controls: Go Both (G+R): Left Hand

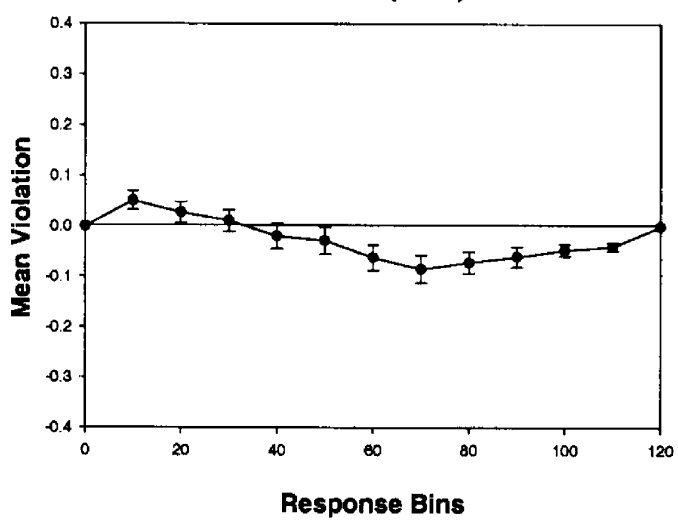

Controls: Go Both $(G+R)$ : Right Hand

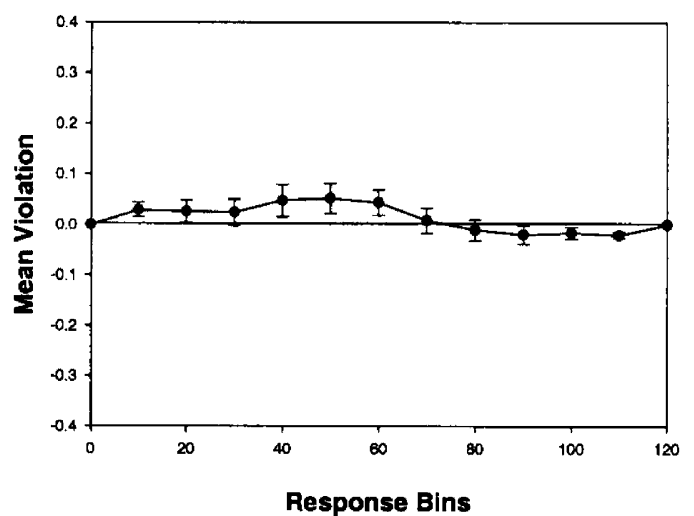

Fig. 2. Mean Race-model violations for 14 control subjects with error bars. Go-Both Task. 


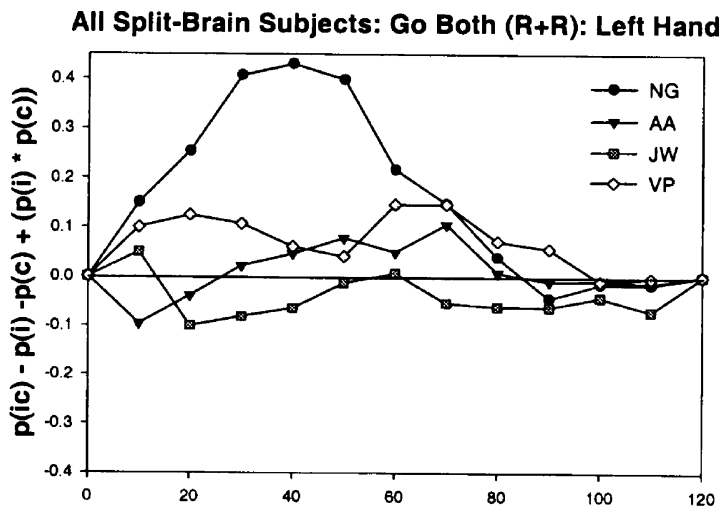

All Split-Brain Subjects: Go Both (R+R): Right Hand

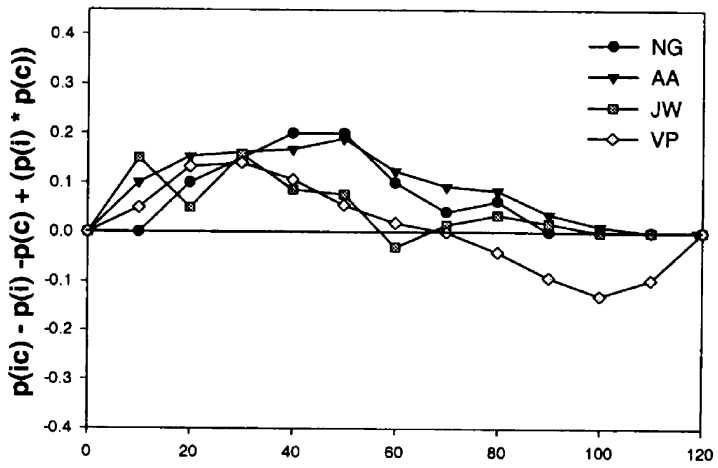

All Split-Brain Subjects: Go Both $(G+G)$ : Left Hand

All Split-Brain Subjects: Go Both $(G+G)$ : Right Hand
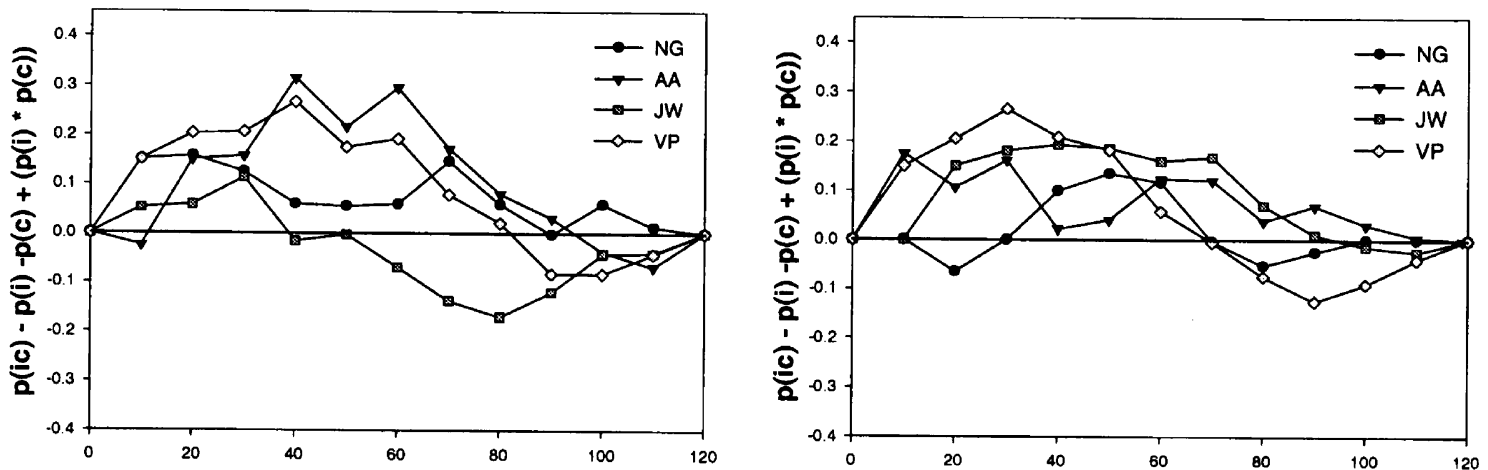

All Split-Brain Subjects: Go Both $(R+G)$ : Left Hand

All Split-Brain Subjects: Go Both $(R+G):$ Right Hand
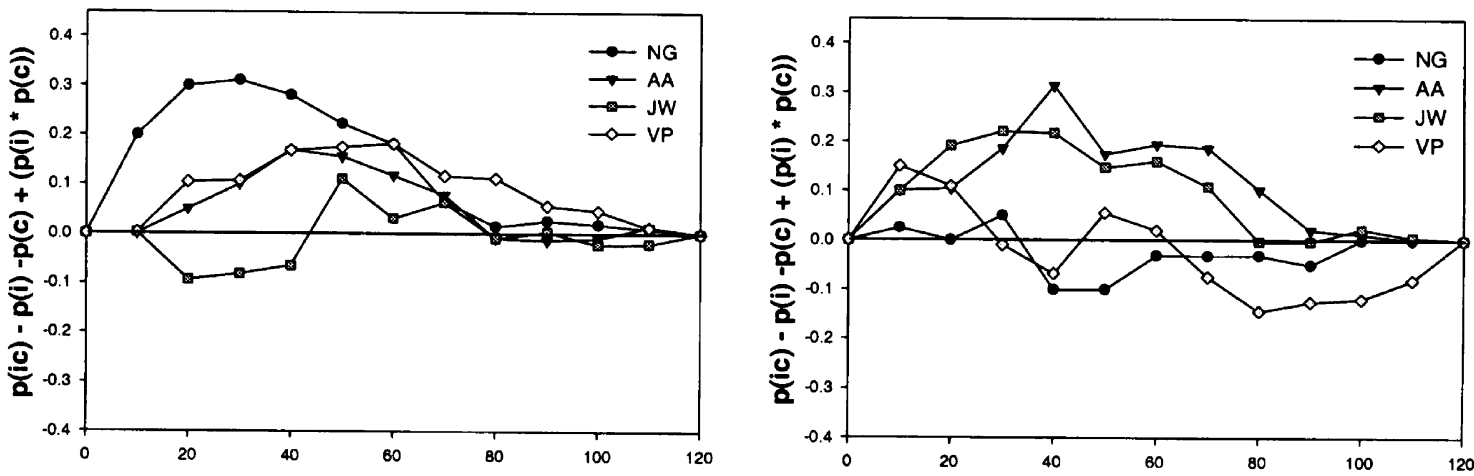

All Split-Brain Subjects: Go Both (G+R): Left Hand

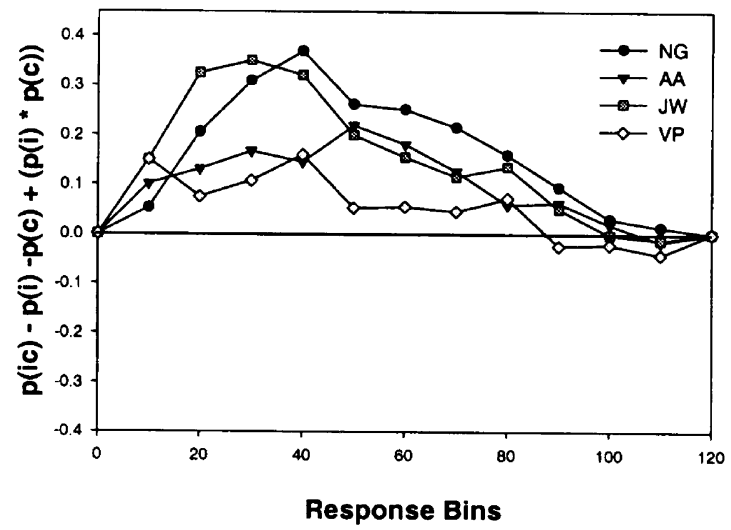

All Split-Brain Subjects: Go Both $(G+R)$ : Right Hand

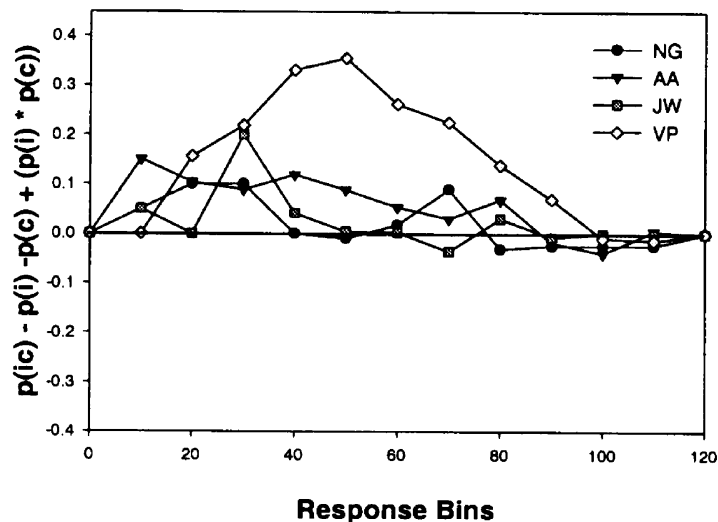

Fig. 3. Race-model violations for all commissurotomized and callosotomized subjects. Go-Both Task. 
race-model violations that never exceeded two standard errors greater than zero.

Cumulative probabilities were also calculated for each split-brained subject. The plots in Fig. 3 combine the

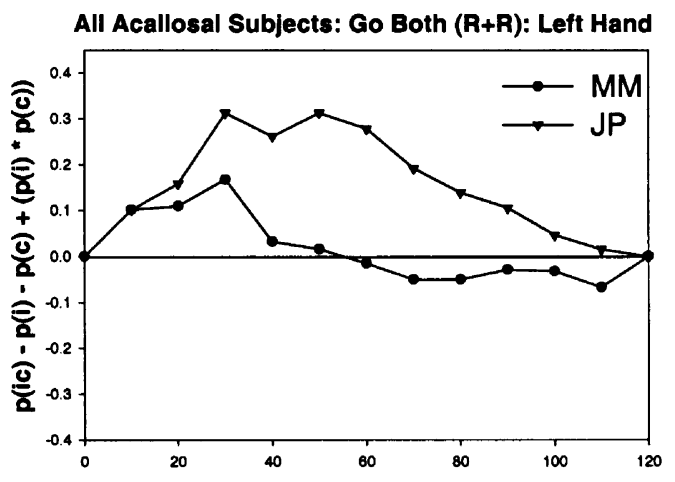

All Acallosal Subjects: Go Both $(G+G)$ : Left Hand

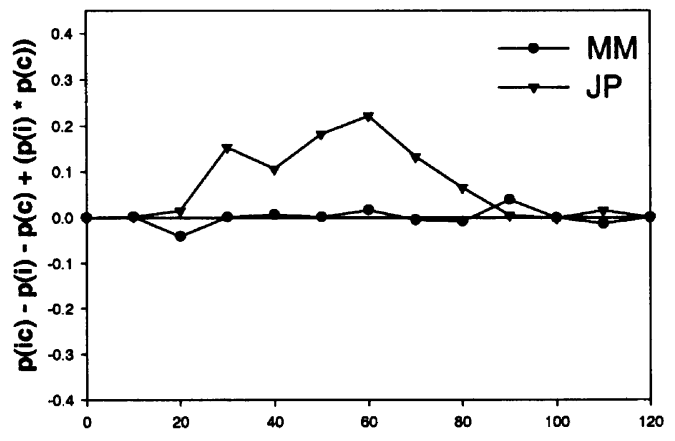

All Acallosal Subjects: Go Both $(R+G)$ : Left Hand

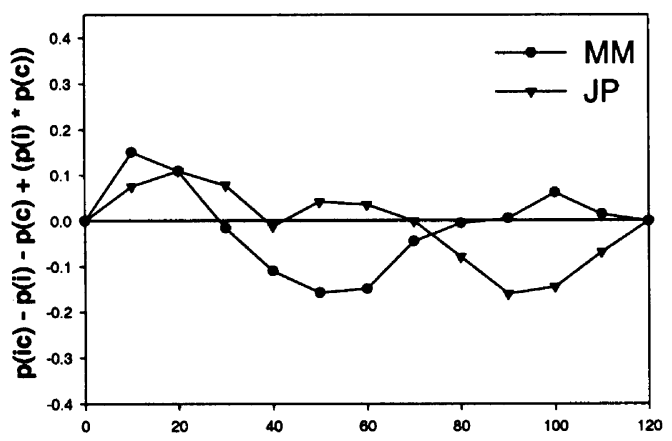

All Acallosal Subjects: Go Both $(G+R)$ : Left Hand

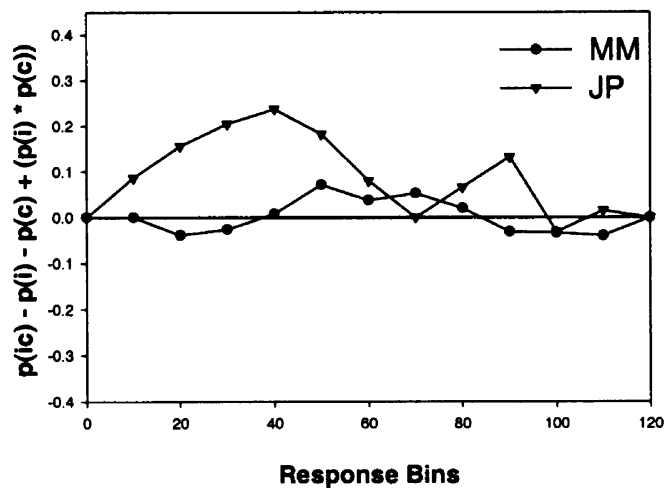

race-model violations shown by the two commissurotomized subjects and the two callosotomized subjects. Each of the eight stimulus combinations shows violations by all four subjects. In addition, each split-brained subject produced

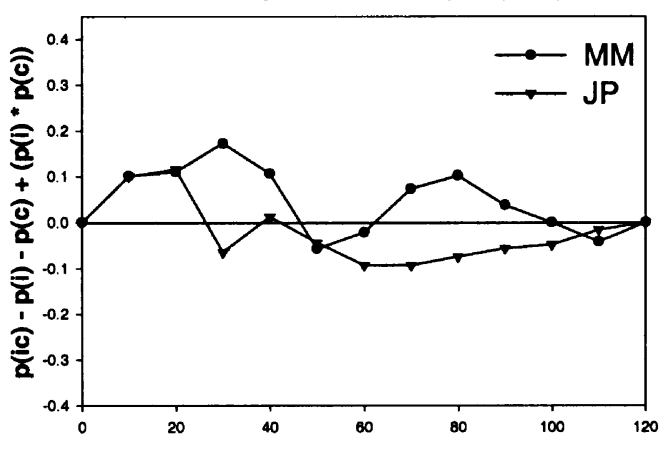

All Acallosal Subjects: Go Both $(G+G)$ : Right Hand

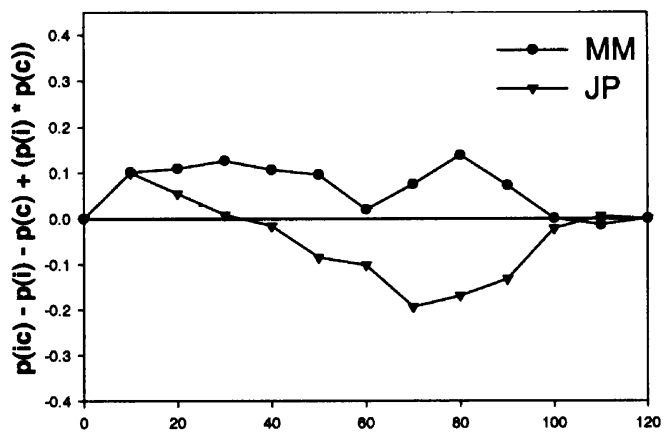

All Acallosal Subjects: Go Both $(R+G)$ : Right Hand

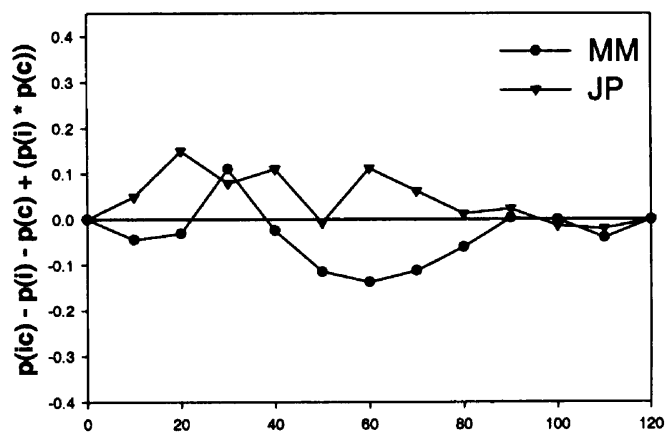

All Acallosal Subjects: Go Both (G+R): Right Hand

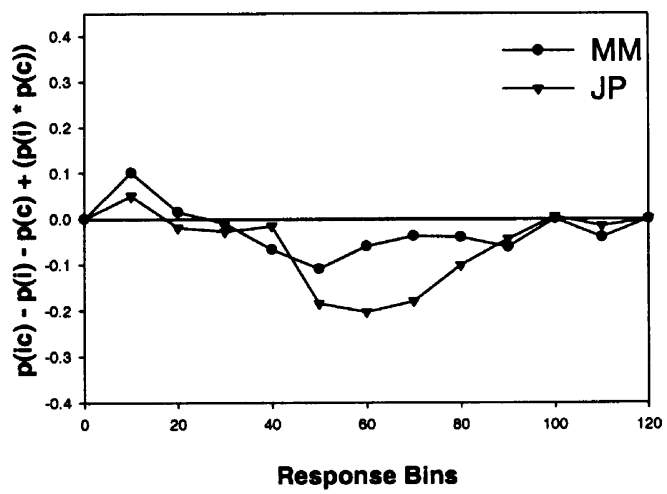

Fig. 4. Race-model violations for all acallosal subjects. Go-Both Task. 
violations that were several times larger than those shown by the control subjects, in at least one stimulus combination.

Race-model violations in the RTs of the two acallosal subjects are shown in Fig. 4. Although the degree of violation seems much more variable for these two subjects than for the split-brained subjects, in general violations are greater than those shown by control subjects, even for J.P. who showed the same redundancy gain as measured by median RT as control subjects. M.M. produced slightly larger race-model violations for identical-stimuli displays than for non-identical-stimuli displays.

\subsection{Discussion}

All of the split-brained or acallosal subjects produced CUDs that were significantly longer than that of the control group. A consistent pattern is discernible in the size of the overall CUD. For the surgical split-brained subjects, the greater the degree of hemispheric disconnection (commisssurotomy $>$ callosotomy), the longer the CUD. This is presumably due to differences in the availability and efficiency of the extra-callosal pathways used for inter-hemispheric transmission in these subjects. For commissurotomized subjects N.G. and A.A., neither the anterior commissure nor the corpus callosum is available. For callosotomized subjects J.W. and V.P., only the corpus callosum is unavailable. Of the split-brained or acallosal subjects, the CUD is smallest for M.M. and J.P. In these acallosal subjects the anterior commissure, or sub-cortical pathways, may have developed greater-than-normal efficiency at transferring information between hemispheres, to compensate for the lack of normal callosal routes. Thus, the CUD in this two-target task seems to be a good index of hemispheric disconnection.

This study showed that split-brained subjects produce redundancy gains when presented with bilateral-redundant stimuli. The two commissurotomized subjects N.G. and A.A. and the callosotomized subject V.P. actually produced significantly larger calculated redundancy gains than the control group. The calculated redundancy gains produced by the remaining subjects, J.W., M.M. and J.P., were of comparable size to those seen in the control subjects' data. Moreover, the violations of the race model were greater for the split-brained or acallosal subjects than the control group. These large violations mean that probability summation cannot account for the redundancy gains seen for these subjects. In turn, this implies that neural summation is responsible for the relatively fast RTs to bilateral-stimuli produced by split-brained or acallosal subjects.

Only one subject, M.M., showed a consistent effect of colour on the redundancy gain, with redundancy gain for same-colour displays exceeding that seen with differentcolour displays. This suggests that the redundancy gain in M.M. is mediated by cortical structures that are colour responsive, and does not reflect a simple summation of activation from luminant stimuli at a sub-cortical site. Activation of extrastriate cortex has been previously implicated in neural summation in the acallosal brain [17]. Note, however, that M.M.'s redundancy gain for different-colour displays $(16 \mathrm{~ms})$ was still slightly larger than that shown overall by the control subjects $(15 \mathrm{~ms})$. Therefore, it seems that stimuli do not need to be the same colour in order for redundancy gains to occur. This result gives us a baseline with which to compare the results of the second experiment, in which both stimulus colour and the required response were manipulated.

\section{Experiment 2}

The second experiment extends the investigation of the redundancy gain in the split brain. In this experiment, coloured stimuli, identical to those used in Experiment 1, were presented. Subjects were required to respond only when presented with a stimulus of target colour, regardless of whether it was presented in conjunction with a stimulus of non-target colour or not. Hence, this task is known as the Go/No-Go Task.

The critical question addressed by this experiment concerns the effects of different-colour displays on RT, or displays in which redundant stimuli, but not redundant targets, are presented. We found that in the Go-Both paradigm of Experiment 1, different-colour displays produced redundancy gains that were comparable to those seen with identical-stimuli displays. If we find that in the Go/No-Go paradigm these same mixed displays do not produce a facilitation in RT, we could conclude that redundant response processes are necessary for neural summation to occur and redundant sensory activation alone is not sufficient.

\subsection{Method}

\subsubsection{Subjects}

The subjects were the same as in Experiment 1.

\subsubsection{Stimuli and procedure}

The same stimuli, luminance values and experimental set-ups that were used in the Go-Both Task were used in the Go/No-Go Task.

There were two versions, one in which green was the target colour (Go-Green version) and one in which red was the target colour (Go-Red version). Stimuli of the target colour were termed "Go" stimuli, while non-target colour stimuli were known as "No-Go" stimuli. Each of the two versions was completed with each response hand, the combination order being counterbalanced across subjects. Each version consisted of four blocks of 80 trials. This resulted in 40 randomly presented trials of each of eight stimulus types, for each combination of target colour and response hand. Catch trials were not presented. As in Experiment 1, stimuli were either unilateral (for example, a single green stimulus in the left visual field), or bilateral (two stimuli of same or different colour, one in each of the left and right visual fields). 
There were, therefore, four different unilateral stimulus displays (Green Left, Green Right, Red Left, Red Right) and four different bilateral displays (Green + Red, Red + Green, Green + Green, Red + Red). A practice block of eight trials was completed prior to beginning each version of the experiment.

Experimental blocks were initiated by pressing the spacebar. The fixation cross appeared for $1000 \mathrm{~ms}$ before the stimuli were flashed for $133 \mathrm{~ms}$. The screen was then cleared and remained blank for $1000 \mathrm{~ms}$. During this time the subject could either respond by pushing the spacebar if a stimulus of the target colour was presented, or withhold a response if a non-target-colour stimulus was presented. If a correct response was made, a 500-Hz tone was presented for $200 \mathrm{~ms}$. Correctly withholding a response to displays featuring only non-target-colour stimuli did not result in a tone. Incorrect responses (both misses and false alarms) triggered a $200-\mathrm{Hz}$ tone for $500 \mathrm{~ms}$. Trials on which errors occurred were re-run during the block in which the trial was presented, so as to ensure that equal numbers of correct responses were recorded for each condition. RTs were recorded from stimulus onset. RTs of less than $133 \mathrm{~ms}$ (that is, while the stimuli were still on the screen) were treated as anticipations and discarded. A 200-ms delay followed the response period, after which the fixation cross reappeared for the next trial.

\subsection{Results}

\subsubsection{Errors}

Errors in the Go/No-Go Task consisted of failing to make a response after a target had been presented (a miss), or responding to the presentation of a No-Go stimulus alone (a false alarm). The total number of these errors made by each split-brained or acallosal subject, and the mean number of errors made by control subjects, are shown in Table 3.

The split-brained subjects, particularly the commissurotomized subjects N.G. and A.A., made considerably more errors than the control subjects. For these two subjects, the number of false-alarm errors was less than the number of misses. This suggests that these subjects were attempting to respond to the presence of a target, however imperfectly, and not responding indiscriminately on each trial. The total number of misses made by A.A. was inflated by the session in which A.A. responded to red targets with his left hand.

Table 3

Mean number of errors made by control subjects and total errors made by each split-brained or acallosal subject for the Go/No-Go Task

\begin{tabular}{lcl}
\hline Subject & Misses & False alarms \\
\hline Controls & 1.07 & 13.93 \\
N.G. & 131 & 15 \\
A.A. & 133 & 84 \\
J.W. & 25 & 40 \\
V.P. & 10 & 22 \\
M.M. & 5 & 12 \\
J.P. & 10 & 3 \\
\hline
\end{tabular}

Nearing the end of this block A.A. repeatedly failed to respond appropriately and reported not seeing the target. The last 14 trials consisted of eight presentations of a red target in the left visual field and six presentations of a red target in the left visual field, accompanied by a green distractor in the right visual field. As A.A. did not respond to these targets, the trials were repeatedly presented, resulting in a large number of missed trials. After it was established that A.A. could not discriminate the target on the remaining trials, the block was terminated. The 14 trials were then removed from the dataset.

\subsubsection{Reaction times}

Median RTs were calculated for all experimental conditions, separately for each control subject and each splitbrained or acallosal subject. Averages across all conditions were then calculated for each subject and the control group. A.A.'s median RTs with his left hand were calculated from a reduced dataset, due to his failure to fully complete one block. CUDs were calculated from these medians by subtracting each subject's RT to unilateral-stimuli presented on the same (ipsilateral) side as their response hand, from the subject's RT to stimuli which appeared on the side opposite (contralateral to) their response hand. Redundancy gains were calculated by subtracting each subject's median RT to bilateral (target + target) stimuli from their fastest median RT to the corresponding unilateral-stimuli. Table 4 shows the CUDs, redundancy gains and median RTs for all subjects averaged across display condition and response hand.

\subsubsection{The crossed-uncrossed difference (CUD). A one-} sample $t$-test was carried out on the calculated CUDs from the control subjects' RTs. The mean CUD again differed significantly from zero only on a directional test, $t(13)=$ 1.928, $P=0.076$.

Separate independent-samples $t$-tests compared each split-brained or acallosal subject with the control group, so that each individual subject was treated as a separate group. All of the split-brained and acallosal subjects produced significantly greater CUDs than the control group, as indicated by asterisks alongside each subject's overall CUD in Table 4.

Table 4

Average median RT, CUD and redundancy gain in milliseconds for all subjects in the Go/No-Go Task

\begin{tabular}{llcl}
\hline & Average median RT & CUD & Redundancy gain \\
\hline Controls & 331 & 3 & $21^{* *}$ \\
N.G. & 520 & $146^{* *}$ & $41^{*}$ \\
A.A. & 528 & $64^{* *}$ & $56^{* *}$ \\
J.W. & 434 & $54^{* *}$ & 25 \\
V.P. & 434 & $17^{*}$ & 38 \\
M.M. & 396 & $28^{* *}$ & 17 \\
J.P. & 425 & $32^{* *}$ & 25 \\
\multicolumn{2}{r}{$P<0.05}$. & & \\
$\quad$ & &
\end{tabular}


3.2.2.2. Redundancy gain. A one-sample $t$-test was carried out on the overall calculated redundancy gains for same-colour (target + target) displays. The control subjects produced a significant overall redundancy gain of $21 \mathrm{~ms}$, $t(13)=9.447, P<0.001$ (significance indicated by double asterisk in Table 4).

Independent-samples $t$-tests compared each split-brained or acallosal subject with the controls, and treated each individual subject as a separate group. Asterisks alongside the value for overall redundancy gain in Table 4 indicate significant group interactions for N.G. and A.A. V.P.'s overall redundancy gain was not significantly greater than that of the control group, but the difference approached significance, $t(13)=1.974, P=0.07$.

3.2.2.3. Different-colour displays: control subjects. In order to determine whether the inclusion of a non-target stimulus in the display decreased RT, as redundant target stimuli did, RTs for responses to unilateral target stimuli were compared with RTs to the same stimuli, presented opposite non-target stimuli.

Mean RTs were calculated for each condition in which a unilateral-target or bilateral-mixed (target plus non-target) stimuli were presented. These means were calculated separately for each control subject. Means were used so the test that was applied to the data from the control subjects was based on the same measure of central tendency as the subsequent analyses performed on the raw data from each split-brained subject. A repeated-measures analysis of variance was carried out on the data from control subjects and included the factors of display type (unilateral-target or bilateral-mixed) and target position relative to response hand (crossed or uncrossed). Control subjects showed a significant effect of target position, $F(1,13)=6.015, P=$ 0.029 , with responses to crossed targets taking $347 \mathrm{~ms}$ on average, compared to $343 \mathrm{~ms}$ for uncrossed targets. The effect of display type approached significance, $F(1,13)=$ $4.343, P=0.057$. Average RT to different-colour displays (344 ms) was $3 \mathrm{~ms}$ faster than RT to unilateral-target displays (347 ms). Therefore, the inclusion of a non-target stimulus in the display did not significantly decrease RT for the control subjects.

3.2.2.4. Different-colour displays: split-brained or acallosal subjects. The critical question that this experiment addresses is whether different-colour displays produce redundancy gains in the split-brained and acallosal subjects. Separate univariate analyses of variance were run on each split-brained or acallosal subject's raw RT data, and included the factors of display type (unilateral-target or bilateral-mixed) and target position. These analyses allowed the effect of non-target stimuli on RT to be investigated separately for each split-brained or acallosal subject.

N.G. showed no overall effect of a redundant non-target stimulus on RT, $F(1,636)=0.089, P=0.766$. There was a significant effect of target position, $F(1,636)=135.508$,
$P<0.001$. N.G. was $153 \mathrm{~ms}$ slower at responding to crossed targets than to uncrossed targets.

J.W. showed an overall effect of display type, $F(1,636)=$ $19.805, P<0.001$. Mean RT to displays containing redundant non-target stimuli was $476 \mathrm{~ms}$, while RT to single targets was $444 \mathrm{~ms}$. J.W. also showed an overall effect of target position, $F(1,636)=165.745, P<0.001$, with uncrossed targets being responded to $92 \mathrm{~ms}$ faster than crossed targets. The factors of display type and target position also interacted, $F(1,636)=14.213, P<0.001$. The retardant effect of redundant non-target stimuli was greater when targets were crossed from, and non-target stimuli were ipsilateral to, the response hand $(59 \mathrm{~ms})$, compared to when non-target stimuli were presented contralateral to the response hand (5 ms).

V.P. showed a similar retardant effect of non-target stimulus presentation, $F(1,636)=5.504, P=0.019$. Mixed displays of targets and non-target stimuli were responded to $21 \mathrm{~ms}$ slower than targets alone. Target position was also significant, $F(1,636)=12.265, P<0.001$, with uncrossed stimuli being responded to faster than crossed stimuli (crossed $=484 \mathrm{~ms}$, uncrossed $=453 \mathrm{~ms})$. The factors of display type and target position also interacted, $F(1,636)=$ $8.160, P=0.004$. When targets were contralateral to the response hand, and No-Go stimuli ipsilateral, the inclusion of a redundant non-target stimulus in the display slowed RT by $47 \mathrm{~ms}$. When targets were ipsilateral to the response hand, non-target stimuli facilitated performance by only $4 \mathrm{~ms}$.

M.M. showed no overall effect of non-target stimulus presentation, $F(1,636)=2.225, P=0.136$. The effect of target position was significant, $F(1,636)=34.539, P<$ 0.001 , with uncrossed stimuli being responded to $33 \mathrm{~ms}$ faster than crossed stimuli.

Although J.P. did not show any main effect of display type on RT, $F(1,636)=0.092, P=0.762$, the interaction of display type and target position did approach significance, $F(1,636)=3.557, P=0.060$. When targets were crossed from the response hand, the inclusion of an uncrossed non-target stimulus in the display slowed RT by $10 \mathrm{~ms}$. When the situation was reversed and targets were uncrossed, the inclusion of a non-target stimulus facilitated RT by $12 \mathrm{~ms}$.

An unweighted-means univariate analysis of variance was carried out on the data from A.A., avoiding problems with the unequal numbers of RTs in each condition. A.A. showed an overall effect of display type, $F(1,622)=8.557$, $P=0.004$. His responses were, on average, quicker when non-target stimuli were presented opposite targets $(547 \mathrm{~ms})$, than when targets were presented alone $(576 \mathrm{~ms})$. The effect of target position was significant, $F(1,622)=50.878$, $P<0.001$, with uncrossed stimuli being responded to $33 \mathrm{~ms}$ faster than crossed stimuli.

In summary, there was little evidence for a consistent redundancy gain with different-colour stimuli displays for either control or split-brained subjects. J.W.'s and V.P.'s RTs were slowed by the presence of a non-target. Only 
one commissurotomized subject, A.A., showed a significant benefit in overall RT when non-target stimuli were presented.

\subsubsection{Cumulative probabilities}

As testing the race model requires two distributions of unilateral-stimuli, and as responses to unilateral-stimuli were only made when the stimulus was of target colour, the race model was only tested for bilateral-target displays. Cumulative probability functions were calculated for responses to crossed, $P_{\mathrm{c}}$ and uncrossed, $P_{\mathrm{i}}$ unilateral-stimuli, and the corresponding bilateral display, $P_{\text {ic }}$. This was done for each combination of hand and target colour.

Fig. 5 plots the mean of the expression $P_{\mathrm{ic}}-P_{\mathrm{i}}-P_{\mathrm{c}}+$ $\left[P_{\mathrm{i}} P_{\mathrm{c}}\right]$ with standard error bars for all 14 control subjects. Target-stimulus colour is indicated for each plot (Go Green or Go Red), as is response hand. Any point above the horizontal zero line indicates a violation of the race model. All four plots show some violation and, in three of the plots (Go Green with each hand and Go Red with the left hand), violations are greater than two standard errors from zero. The
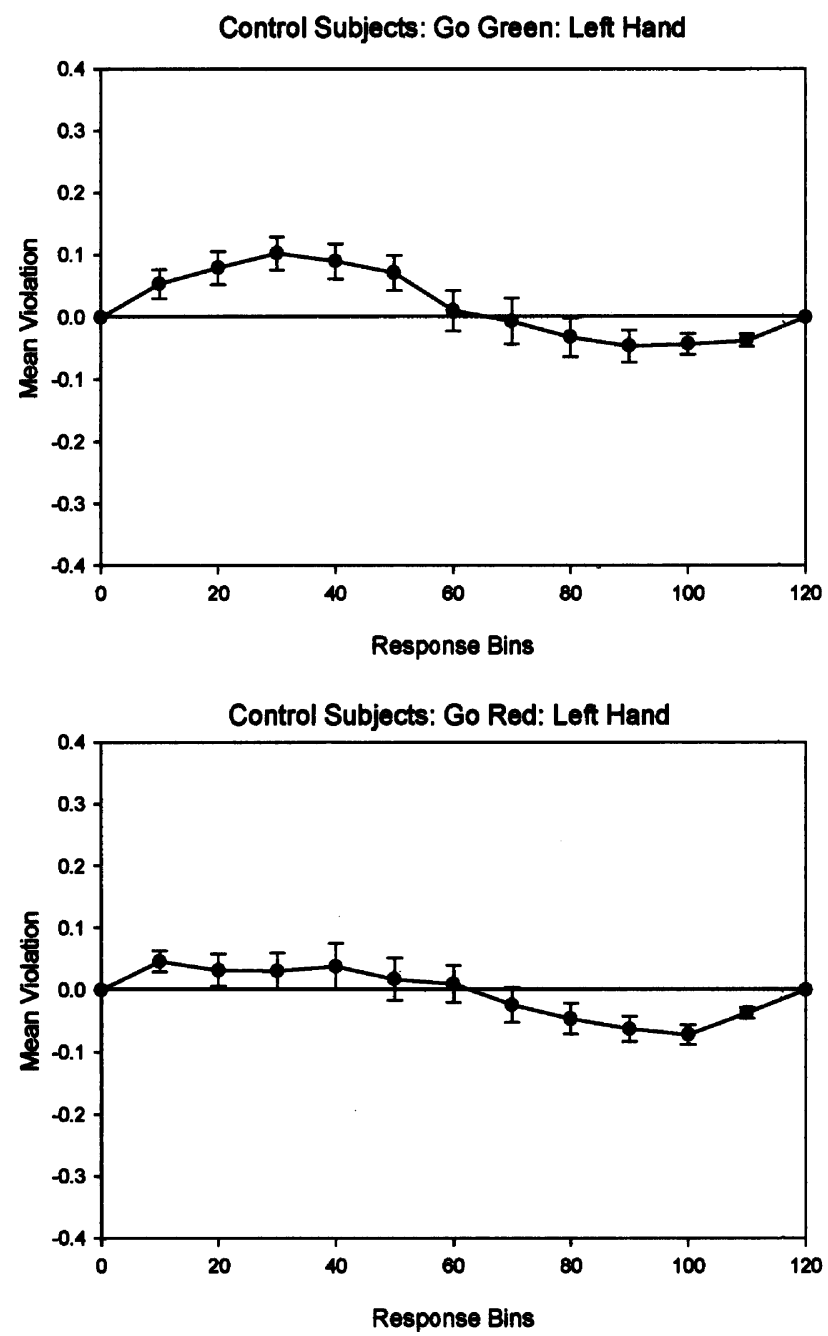

greatest violations (reaching $P=0.1$ ) tended to occur in the fastest bins, while the mean violation in the slower bins tends to fall close to, or beneath, zero.

Cumulative probabilities were calculated for the split-brained subjects in the same manner as for control subjects. As A.A. failed to fully complete the experiment when using his left hand to respond to red stimuli, cumulative probabilities for this subject were calculated from a total pool of 112 responses in this condition. Violations of the race model for all four split-brained subjects are shown together in Fig. 6. The violations are much larger than those shown by the control subjects, consistent with the result of the analysis of variance carried out on the redundancy gains. The race model was violated by all subjects, for all four combinations of target colour and response hand.

Violations of the race model are plotted for acallosal subjects in Fig. 7. Overall the degree of violation is greater than that shown by the control subjects, although not to the same degree as for the split-brained subjects. This finding mirrors the results of the analysis of variance of calculated redundancy gains, in which neither of the acallosal subjects
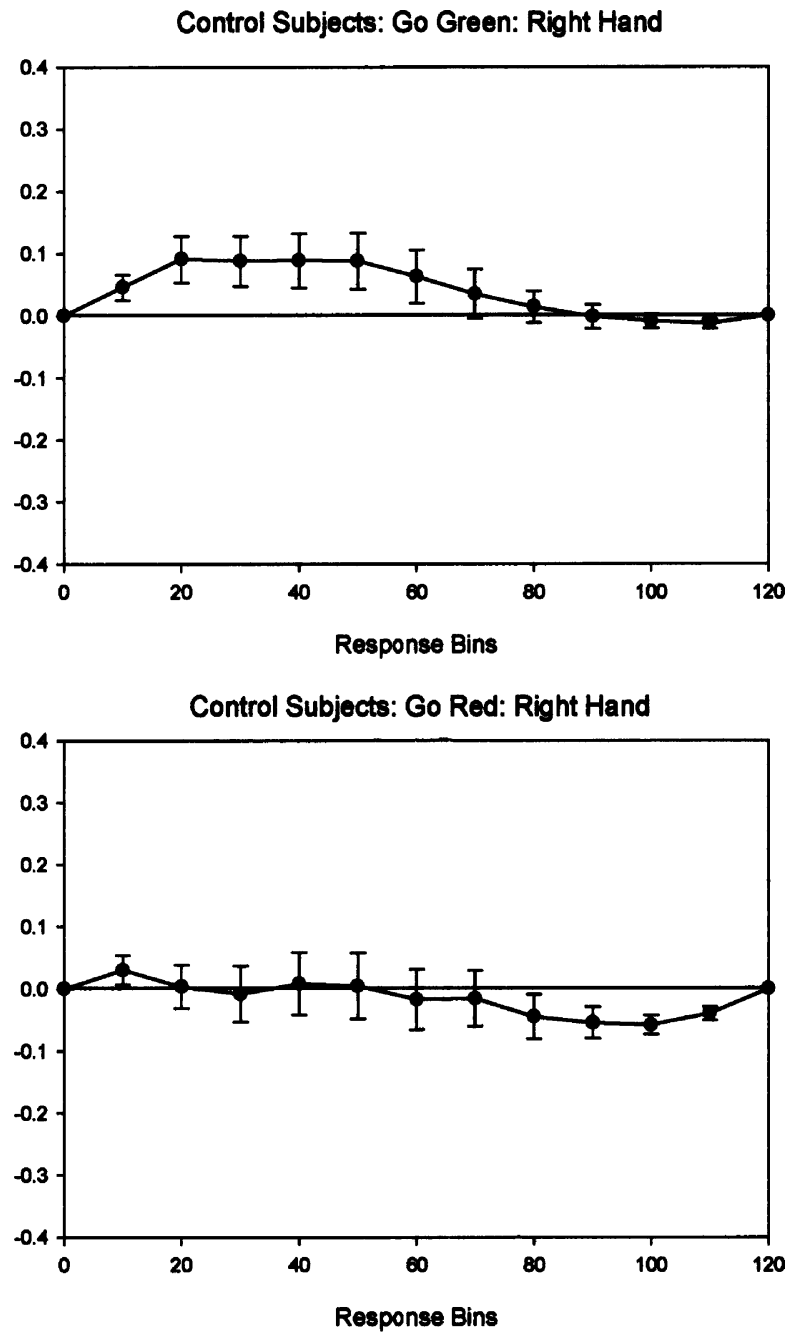

Fig. 5. Mean violation of the race model for 14 control subjects with standard-error bars. Go/No-Go Task. 

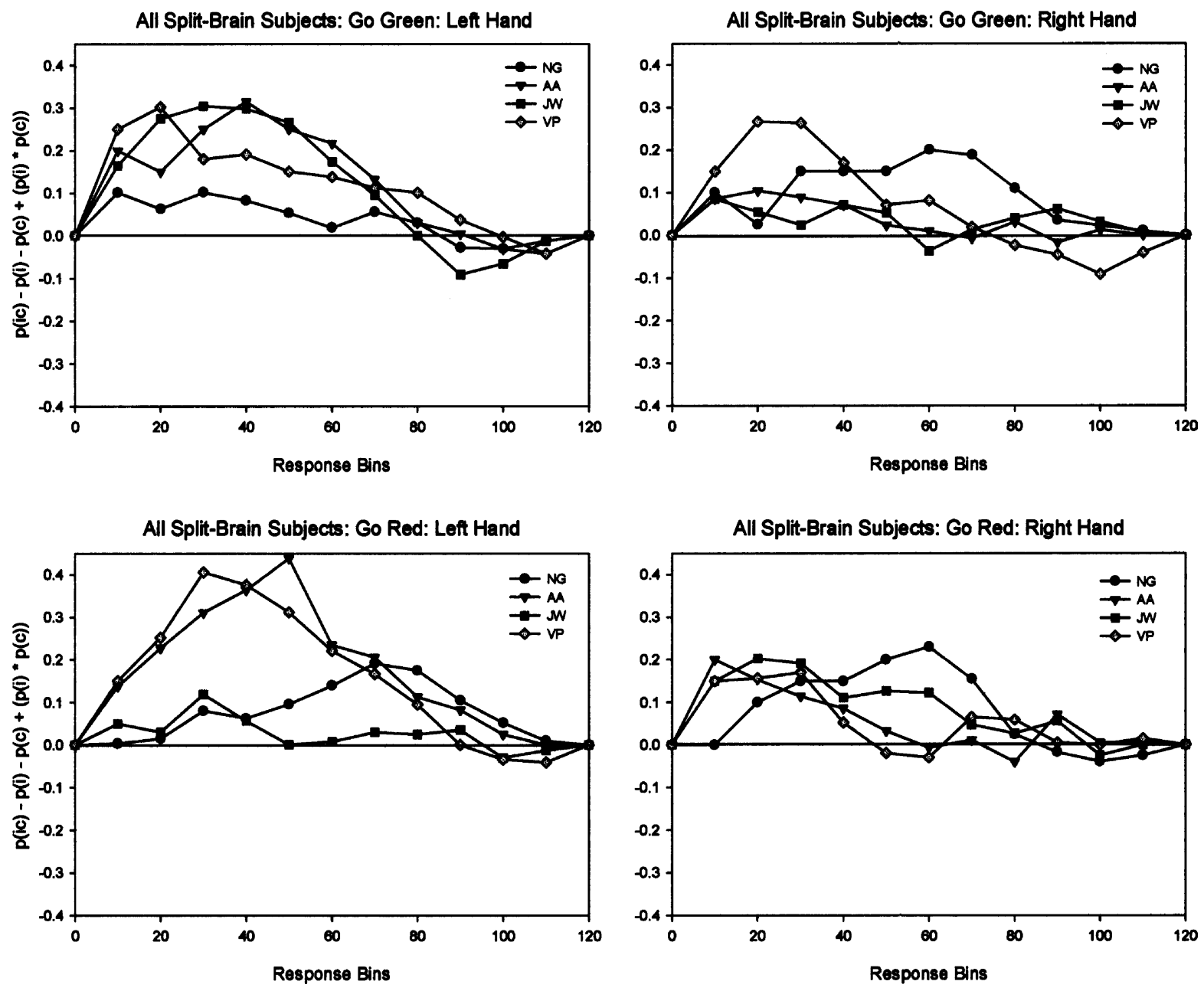

Fig. 6. Race-model violations for all commissurotomized and callosotomized subjects. Go/No-Go Task.

demonstrated a significantly greater redundancy gain than that shown by control subjects.

\subsection{Discussion}

All of the split-brained and acallosal subjects showed CUDs that were significantly greater than that shown by the control group. As in the Go-Both Task, the length of the CUD generally increased as the degree of neurological separation of the two hemispheres increased from callosal agenesis through callosotomy to commissurotomy. However, this pattern did not hold for callosotomized subject J.W. who showed a CUD that was smaller than any other split-brained or acallosal subject in the study and smaller than previously reported for this subject [32].

The control subjects and the split-brained or acallosal subjects were faster at responding to bilateral target stimuli than to single target stimuli. In this task, unlike the Go-Both Task, only the two commissurotomized subjects showed significantly larger redundancy gains than the control subjects. This is probably due to the fact that the control subjects showed a larger gain in the Go/No-Go Task than in the Go-Both Task, and not because the split-brained or acallosal subjects produced smaller gains in the Go/No-Go Task. In fact, all of the individual subjects, with the exception of M.M., also showed larger gains for the Go/No-Go Task than the Go-Both Task.

The effect on RT of presenting redundant-mixed displays is critical to the question of what kind of activation converges in producing the redundancy gain. Only one subject (A.A.) was significantly faster at responding to target stimuli when these stimuli were accompanied by a non-target stimulus. The lack of RT facilitation seen for the remaining subjects in this condition contrasts with the large redundancy gains produced by the control subjects and all the split-brained or acallosal subjects, when bilateral-target stimuli were presented. The responses of the two callosotomized subjects (J.W. and V.P.) were slowed by the presence of a non-target stimulus, suggesting that these redundant stimuli actually resulted in response inhibition. While non-target stimuli were not explicit "stop" signals, they may, once identified, initiate an inhibitory process that overrides any response being prepared to the luminance onset.

The lack of facilitation demonstrated with displays of different-colour stimuli in the Go/No-Go Task cannot be 

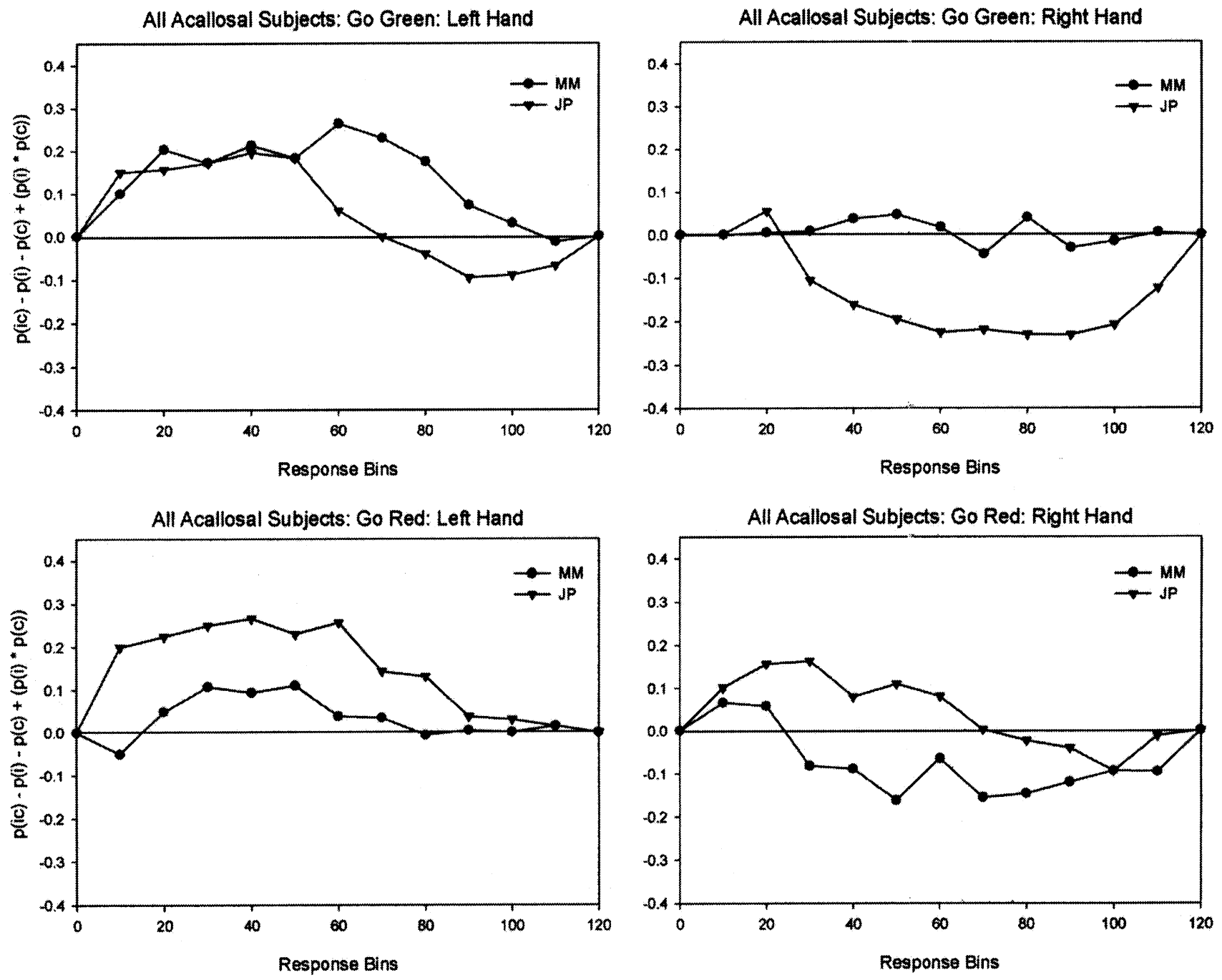

Fig. 7. Race-model violations for all acallosal subjects. Go/No-Go Task.

attributed to a simple effect of colour, as the Go-Both experiment clearly demonstrated that displays of bilateral different-colour stimuli produced redundancy gains equivalent to those seen with identical-colour stimuli. Instead, the results of the Go/No-Go Task suggest that only redundant target stimuli are able to produce large gains in RT. Thus, redundant response activation is necessary for large RT facilitation to occur, while redundant sensory activation alone is not sufficient. This suggests that the neural summation underlying the redundancy gain is probably the result of the convergence of response processes initiated by each hemisphere.

\section{Comparison of redundancy gains for experiment 1 and experiment 2}

In order to conclude that the lack of facilitation seen with different-colour displays in the Go/No-Go paradigm was due to the lack of converging response activation and not due simply to the nature of the task, we must first rule out the possibility that redundancy gains were smaller in the Go/No-Go Task than in the Go-Both Task. To check this, a repeated measures analysis of variance was carried out on the overall redundancy gains produced for displays of identical stimuli in each of these tasks. That is, the overall redundancy gain for displays in which both stimuli were either red or green in the Go-Both Task was compared with the overall redundancy gain for displays in which both stimuli were either red or green in the Go/No-Go Task. These redundancy gains are shown in Table 5. A separate analysis compared redundancy gains on the two tasks for the control group alone. Further analyses compared the effect of task for each split-brained or acallosal subject against the control group.

The control group showed a significant effect of task on the size of the redundancy gain, $F(1,13)=8.102, P=$ 0.014 , indicated by asterisks. The mean redundancy gain was $6 \mathrm{~ms}$ greater for the Go/No-Go Task than the Go-Both Task. 
Table 5

Redundancy gain in milliseconds for all subjects with identical-stimuli displays in the Go-Both and Go/No-Go Tasks

\begin{tabular}{lll}
\hline & Go-Both & Go/No-Go \\
\hline Controls & 15 & $21^{* *}$ \\
N.G. & 37 & 41 \\
A.A. & 43 & 56 \\
J.W. & 10 & 25 \\
V.P. & 38 & 38 \\
M.M. & 32 & $17^{*}$ \\
J.P. & 15 & 25 \\
\hline
\end{tabular}

${ }^{*} P<0.05$

${ }^{* *} P<0.01$.

Four of the six individual subjects, N.G., A.A., J.W., and J.P., also showed greater redundancy gains in the Go/No-Go Task than the Go-Both Task, although for none of these subjects was the task difference significantly greater than for the control group. Callosotomized subject V.P. produced equal redundancy gains for the two tasks. Acallosal subject M.M. showed a larger redundancy gain for the Go-Both Task than for the Go/No-Go Task and this resulted in a significant interaction between task and group, $F(1,13)=7.504, P=$ 0.017 , indicated by an asterisk.

Thus, only one subject, M.M., showed a smaller redundancy gain in the Go/No-Go Task than in the Go-Both Task. But, in the Go/No-Go Task, M.M. still produced a redundancy gain which was close to that shown by normal subjects. It therefore, seems unlikely that the lack of facilitation observed in the responses of subjects to target stimuli, which were presented in the presence of non-target stimuli, was due simply to the nature of the task.

\section{General discussion}

\subsection{Processing stage}

The experiments reported here show that neural summation is not greatly affected by stimulus colour and that, only when redundant stimuli that are associated with a response are presented, is there evidence for a large redundancy gain. Thus, neural summation of response-related processes, rather than earlier perceptual processes, probably underlies the redundancy gain.

There are, however, two stages of activation that could be associated with the making of a response. Summation may be between relatively early decisional processes, during which targets are identified as such and preparation for a response is initiated. Alternatively, summation may occur between later motor processes themselves. Previous research suggests that summation is more likely to occur at the decisional stage. One study has shown a redundancy gain in response force, suggesting the summation of motor processes [14], but a subsequent study failed to replicate this finding [27]. Analysis of ERPs has also failed to detect coactivation in late motor processes [24,27]. In addition, Cavina-Pratesi et al. [3] found a redundancy gain in a simple RT task that did not require a response. Redundant visual "stop" signals were more likely to successfully inhibit responses to a preceding auditory stimulus than single "stop" signals. Thus, there is evidence for a redundancy gain in the inhibition of a response.

Therefore, on balance, it seems likely that the redundancy gain effect occurs prior to late motor processes, and consequently, the response-associated redundancy gain seen in our experiments is more likely to be due to coactivation at the decisional stage than at the motor stage. Transfer of information between the hemispheres, which informs each hemisphere that its opposite number is preparing a response to a target stimulus, may underlie the redundancy gain seen in data from callosally intact, split-brained, and acallosal subjects. Redundant target stimuli, presented bilaterally, will initiate response-preparation processes in each hemisphere. A response-preparation process occurring in the hemisphere controlling the response hand may be speeded by spreading activation from a complementary process in the opposite hemisphere, resulting in faster responses to redundant targets.

Since the corpus callosum should allow for greater interaction between the hemispheres, it seems surprising that the redundancy gain is much smaller in normal subjects than it is in the split brain. There are two possible explanations for why this is not so.

Rather than promoting neural summation, the corpus callosum may actually serve to suppress it, although suppression, if it occurred, must have been incomplete as violations of the race model were evident in the data from control subjects. This explanation is supported by the observation that redundancy gains seen in normal subjects sometimes fall well below the predictions of the race model [6-8]. Thus, facilitatory interhemispheric neural summation may proceed sub-cortically, as in the split brain, while interhemispheric inhibition involves the corpus callosum. But as interhemispheric inhibition has been demonstrated in a split-brained subject [32], intactness of the corpus callosum is not essential for this effect to occur.

An alternative explanation is that callosally intact subjects experience neural summation, even with unilateral stimulation. The corpus callosum allows visual input from each visual field to activate the ipsilateral hemisphere, as normal subjects show delayed ipsilateral ERPs [19], while acallosal subjects show very little evidence of ipsilateral ERPs [2] and split-brained subjects show none [20]. It is possible, therefore, that a unilateral stimulus may result in response preparation processes being initiated in both hemispheres in callosally intact subjects, resulting in interhemispheric neural summation even for single stimuli. If this indeed occurs, the fact that normal subjects still show a redundancy gain suggests that the neural summation produced with single stimuli, through callosal transfer of visual activation, is smaller 
than that produced with redundant stimuli presented to each hemisphere.

The size of the CUD and redundancy gain shown by the acallosal subjects, partway between those for normal subjects and those for split-brained subjects, may be due to interhemispheric transfer being degraded, relative to normal, in the acallosal brain, but not to the degree that it is degraded in the split brain. Acallosal subjects do show some visually evoked activation in the hemisphere ipsilateral to stimulation [2,34], and are often able to integrate information presented in the two visual fields $[18,25]$. Therefore, they may show less of a redundancy gain than split-brain subjects because they experience limited summation on single stimuli trials. However, the generally larger redundancy gains shown by M.M. and J.P., when compared to those of the control subjects, suggest that this occurs to a lesser degree than in normal subjects.

Overall the results suggest that the redundancy gain results from the additive interaction of response processing in the two hemispheres, rather than the summation of sensory activation at the superior colliculus, as was suggested by an earlier study [7]. Moreover, the positive relationship between redundancy gain and CUD suggests that the performance benefit gained from presentation of redundant stimuli to each hemisphere is greatest in those subjects in whom normal interhemispheric interactions are disrupted. Thus, the seemingly paradoxical coupling of prolonged interhemispheric transfer with enhanced redundancy gain results from the common origin of the two phenomena, the disruption of the cortical commissures.

\subsection{The neural locus of summation}

Response generation, in a task involving target discrimination, presumably depends on cortical processes in pre-motor and motor areas. Thus, the response-associated neural summation seen in the data from split-brained and acallosal subjects in the present study represents interaction between cortical processes under way in separated hemispheres.

Despite this cortical involvement, the redundancy gain in the split brain must require sub-cortical transmission, allowing activity in one hemisphere to influence activity in its opposite number. This may occur through interhemispheric input to cortico-midbrain circuits involved in producing responses. Premotor and primary motor areas in the cortex, are connected in a complex feedback loop with sub-cortical nuclei in the midbrain and the cerebellum, that serves to modulate cortical motor commands [13]. Premotor and primary motor input to the cerebellum proceeds from the cortex to the pontine nuclei, where it is relayed to the contralateral cerebellar hemisphere through the middle cerebellar peduncle. The cerebellum sends information to both motor and premotor cortex via the ventral lateral nucleus of the thalamus [13]. Although this feedback loop is involved in the planning and execution of more complex movements than simple button-push responses, the dentate nucleus of the cerebellum seems important in the initiation of movement [21]. This feedback loop provides a mechanism whereby bi-hemispheric processing of response-preparation signals may interact. This may result in the criterion level of activation for the production of a response being reached earlier, with redundant stimuli, than is the case with single target stimuli.

Although neural summation proceeds regardless of stimulus mid-line symmetry [33], or stimulus colour similarity (this study), the superior colliculus or other sub-cortical visual centres may still be involved as Corballis [7] found that the effect was eliminated in three split-brained subjects when stimuli were hue changes, equiluminant with the background. Thus, it seems that sub-cortical, visually-responsive structures like the superior colliculus, have to be active for neural summation to occur. The combination of results from the present study, with those of Corballis [7], suggest that, while neural summation is unlikely to simply involve the convergence of perceptual activation at the superior colliculus, cortical-midbrain interactions may be important. In other words, two things seem necessary for violation of the race model; redundant response processes and sub-cortical visual activation. Although the superior colliculus is primarily involved in the production of eye movements [15], rather than button-push responses, its connections with the reticular formation may mean that activation of the superior colliculus plays a role in alerting the brain to the presence of retinal stimulation. This function may be maximised with redundant stimuli. The alerting of both hemispheres with redundant stimuli may have been the mechanism underlying the redundancy gain in commissurotomised subject A.A., as he showed large redundancy gains with mixed stimuli in the Go/No-Go Task.

\section{Acknowledgements}

We wish to thank the subjects for their participation, Michael S. Gazzaniga for access to V.P. and J.W., Dahlia Zaidel and Eran Zaidel for access to N.G. and A.A., and David C. Finlay and Anne Quayle for access to M.M. We also wish to thank Paul Corballis for help in testing V.P. and J.W., and Jeff Hamm for help with data analysis. This research was supported by a grant from the Marsden Fund of New Zealand.

\section{References}

[1] Bogen JE, Scholtz D, Vogel PJ. Completeness of callosotomy shown by Magnetic Resonance Imaging in the long term. Archives of Neurology 1988;45:1203-5.

[2] Brown WS, Jeeves MA, Dietrich R, Burnison DS. Bilateral field advantage and evoked potential interhemispheric transmission in commissurotomy and callosal agenesis. Neuropsychologia 1999;37:1165-80. 
[3] Cavina-Pratesi C, Bricolo E, Prior M, Marzi CA. Redundancy gain in the stop-signal paradigm: implications for the locus of coactivation in simple reaction time. Journal of Experimental Psychology: Human Perception \& Performance 2001;27:932-41.

[4] Clarke JM, Zaidel E. Simple reaction times to lateralized light flashes. Varieties of interhemispheric communication routes. Brain 1989;112:849-70.

[5] Corballis MC. Hemispheric interactions in temporal judgments about spatially separated stimuli. Neuropsychology 1996;10:42-50.

[6] Corballis MC. Hemispheric interactions in simple reaction time. Neuropsychologia 2002;40:423-34.

[7] Corballis MC. Interhemispheric neural summation in the absence of the corpus callosum. Brain 1998;121:1795-807.

[8] Corballis MC, Corballis PM, Hamm J, Barnett KJ. Paradoxical interhemispheric summation in the split brain. Journal of Cognitive Neuroscience 2002;14:1151-7.

[9] Corballis MC, Finlay DC. Interhemispheric visual integration in three cases of familial callosal agenesis. Neuropsychology 2000;14:60-70.

[10] Fendrich R, Gazzaniga MS. Evidence of foveal splitting in a commissurotomy patient. Neuropsychologia 1989;27:273-81.

[11] Forster B, Corballis MC. Interhemispheric transmission times in the presence and absence of the forebrain commissures: effects of luminance and equiluminance. Neuropsychologia 1998;36:925-34.

[12] Gazzaniga MS, Holtzman JD, Deck MDF, Lee BCP. MRI assessement of human callosal surgery with neuropsychological correlates. Neurology 1985;35:1763-6.

[13] Ghez C. The cerebellum. In: Kandel ER, Schwartz JH, Jessell TM, editors. Principles of neural science. Norwalk, CT: Appleton \& Lange; 1991. p. 626-46.

[14] Giray M, Ulrich R. Motor coactivation revealed by response force in divided and focused attention. Journal of Experimental Psychology: Human Perception and Performance 1993;19:1278-91.

[15] Goldberg ME, Eggers HM, Gouras P. The ocular motor system. In: Kandel ER, Schwartz JH, Jessell TM, editors. Principles of neural science. Norwalk, CT: Appleton \& Lange; 1991. p. 660-78.

[16] Grice GR, Reed JM. What makes targets redundant? Perception and Psychophysics 1992;51:437-42.

[17] Iacoboni M, Ptito A, Weekes NY, Zaidel E. Parallel visuomotor processing in the split brain: cortico-sub-cortical interactions. Brain 2000;123:759-69.

[18] Jeeves MA. Callosal agenesis-a natural split brain overview. In: Lassonde M, Jeeves MA, editors. Callosal agenesis: a natural split brain? New York (NY): Plenum Press; 1994. p. 285-99.

[19] Lines CR, Rugg MD, Milner AD. The effect of stimulus intensity on visual evoked potential estimates of interhemispheric transmission time. Experimental Brain Research 1984;57:89-98.
[20] Mangun GR. Neural mechanisms of visual selective attention in humans. Psychophysiology 1995;32:4-18

[21] Meyer-Lohmann J, Hore J, Brooks VB. Cerebellar participation in generation of prompt arm movements. Journal of Neurophysiology 1977;40:1038-50.

[22] Miller J. Channel interaction and the redundant-targets effect in bimodal divided attention. Journal of Experimental Psychology: Human Perception \& Performance 1991;17:160-9.

[23] Miller J. Divided attention: evidence for coactivation with redundant signals. Cognitive Psychology 1982;14:247-79.

[24] Miller J, Ulrich R, Lamarre Y. Locus of the redundant-signals effect in bimodal divided attention: a neurophysiological analysis. Perception \& Psychophysics 2001;63:555-62.

[25] Milner AD. Visual integration in callosal agenesis. In: Lassonde M, Jeeves MA, editors. Callosal agenesis: a natural split brain? New York (NY): Plenum Press; 1994. p. 171-85.

[26] Mohr B, Pulvermueller F, Mittlestaedt K, Rayman J. Multiple simultaneous stimulus presentation facilitates lexical processing. Neuropsychologia 1996;34:1003-13.

[27] Mordkoff JT, Miller J, Roch A-C. Absence of coactivation in the motor component: evidence from psychophysiological measures of target detection. Journal of Experimental Psychology: Human Perception and Performance 1996;22:24-41.

[28] Mordkoff JT, Yantis S. An interactive race model of divided attention. Journal of Experimental Psychology: Human Perception \& Performance 1991;17:520-38.

[29] Perry VH, Cowey A. Retinal ganglion cells that project to the superior colliculus and pretectum in the macaque monkey. Neuroscience 1984;12:1125-37.

[30] Pollmann S, Zaidel E. Redundancy gains for visual search after complete commissurotomy. Neuropsychology 1999;13:246-58.

[31] Raab DH. Statistical facilitation of simple reaction times. Transaction New York Academy of Science 1962;24:574-90.

[32] Reuter-Lorenz PA, Nozawa G, Gazzaniga MS, Hughes HC. Fate of neglected targets: a chronometric analysis of redundant target effects in the bisected brain. Journal of Experimental Psychology: Human Perception \& Performance 1995;21:211-30

[33] Roser M, Corballis MC. Interhemispheric neural summation in the split brain with symmetrical and asymmetrical displays Neuropsychologia 2002;40:1300-12.

[34] Saron CD, Lassonde M, Vaughn HG, Foxe JJ, Alfhors SP, Simpson GA. Interhemispheric visuomotor interaction in callosal agenesis: spatiotemporal patterns of cortical activation. Society for Neuroscience Abstracts 1997;23:1949.

[35] Schneider W. Micro Experimental Laboratory. Pittsburg, PA Psychology Software Tools; 1995. 